\title{
System Designing of Solar Power Sail-craft for Jupiter Trojan Asteroid Exploration*
}

\author{
By Osamu Mori, ${ }^{1)}$ Jun Matsumoto, ${ }^{1)}$ Toshihiro Chujo, ${ }^{1)}$ Hideki Kato, ${ }^{1)}$ Takanao SaIKI, ${ }^{1)}$ Junichiro Kawaguchi, ${ }^{1)}$ \\ Shigeo KAWASAKI, ${ }^{1)}$ Tatsuaki OKADA, ${ }^{1)}$ Takahiro IWATA, ${ }^{1)}$ and Yuki TAKAO ${ }^{2)}$ \\ ${ }^{1}$ Institute of Space and Astronautical Science, Japan Aerospace Exploration Agency, Sagamihara, Japan \\ ${ }^{2)}$ Department of Aeronautics and Astronautics, The University of Tokyo, Tokyo, Japan
}

(Received August 2nd, 2017)

\begin{abstract}
The solar power sail is an original Japanese concept in which electrical power is generated by thin-film solar cells on the sail membrane. It can generate sufficient electric power to drive the high-specific ion engines in the outer planetary region. We propose a landing or sample return mission to explore a Jupiter Trojan asteroid directly using solar power sail. After rendezvousing with a Trojan asteroid, a lander separates from the solar power sail-craft to collect surface and underground samples, and perform an in-situ analysis in Plan-A/B. In addition, the lander delivers samples to the solar power sail-craft to return the sample in Plan-B. This paper shows a system design for the solar power sail-craft and introduces the latest mission analysis.
\end{abstract}

Key Words: Solar Power Sail, Trojan Asteroid, Landing, Sampling, In-situ Analysis

\section{Introduction}

The solar power sail is an original Japanese concept in which electrical power is generated by thin-film solar cells on the sail membrane. JAXA developed "IKAROS," the world's first solar power sail, which demonstrated both photon propulsion and thin-film solar power generation during its interplanetary mission. ${ }^{1)}$ For the next generation of IKAROS, a solar power sail-craft "OKEANOS" is being designed.

For navigation in the outer planetary region, ensuring electric power becomes increasingly difficult and $\Delta \mathrm{V}$ requirements become large. For example, the electric power generated around Jupiter is only $4 \%$ compared to that around Earth when using solar cells. It is difficult to drive ion engines using solar panels in the outer planetary region. The $\Delta \mathrm{V}$ for returning samples from a Jupiter Trojan asteroid is $6000 \sim 7000 \mathrm{~m} / \mathrm{s}$. It is not possible to perform landing or sample return missions to asteroids beyond the main belt using a combination of solar panels and chemical propulsion system, even with a large launch vehicle.

The solar power sail can be an ultra-light power generation system $(1 \mathrm{~kW} / \mathrm{kg})$. It can generate sufficient electric power to drive high-Isp $(7000 \mathrm{sec})$ ion engines in the outer planetary region by attaching thin-film solar cells over the entire surface of the large sail membrane. The solar power sail-craft can be a high-performance propulsion system.

Table 1 shows the system designs of the spacecafts for Jupiter zone explorations. The electrical power of OKEANOS is 10 times larger than that of Juno. The $\triangle \mathrm{V}$ of OKEANOS is 3.5 times larger than that of Juno. However, the dry weights of

(C) 2018 The Japan Society for Aeronautical and Space Sciences ${ }^{*}$ Presented at the 31st International Symposium on Space Technology and Science, June 3-9, 2017, Matsuyama, Japan these spacecrafts are not much different from each other. This table indicates the uniqueness and superiority of the system design using a solar power sail. The spacecraft system using a solar power sail can be utilized for missions to the outer planetary region.

We have been studying the exploration of Jupiter Trojan asteroids using solar power sail since the early 2000s. ${ }^{2)}$ Trojan asteroids are located in long-term stable orbits around the Sun-Jupiter Lagrange points (L4 or L5), and most of them are classified as D- or P-type in taxonomy; considered to being composed of rich materials such as rocks, water ices, and organics. They are the missing links of materials that originate from the inner or outer solar system by planetary migration, ${ }^{3)}$ have an intermediate size and have undergone some degree of aqueous and thermal alteration between the primitive smaller and the evolved larger bodies. They are the key targets to be explored for understanding the evolution process and chemical radial distribution in the solar system, as well as the possible sources of terrestrial oceans and life.

Based on the above, we propose a landing or sample return mission to explore a Jupiter Trojan asteroid directly by OKEANOS ${ }^{4)}$ After rendezvousing with a Trojan asteroid, a lander separates from OKEANOS to collect surface and underground samples, and performs in-situ analysis in Plan-A/B. In addition, the lander delivers samples to OKEANOS to return samples in Plan-B.

NASA selected Lucy $^{5}$ ) for the Discovery program. It is a multi-flyby mission for Jupiter Trojans, but is not a direct mission. The purpose of Lucy is to understand the variation and diversity of Jupiter Trojans by multiple flybys. On the other hand, OKEANOS aims at performing an in-depth investigation by landing and obtaining samples. By combining the results of Lucy and OKEANOS, the scientific output can be maximized as shown in Fig. 1. 
The summary of small celestial body and outer solar system exploration is shown in Table 2. OKEANOS is the only solution for returning samples from the Jupiter zone. The spacecraft system using a solar power sail will lead future solar system exploration.

This paper shows a detailed system design for OKEANOS in detail and introduces the latest mission analysis.

\begin{tabular}{|c|c|c|c|}
\hline Mission & Mass & Electric power at $5.2 \mathrm{AU}$ & $\Delta \mathrm{V}$ \\
\hline Juno & $\begin{array}{l}\text { Wet: } 3625 \mathrm{~kg} \\
\text { Dry: } 1593 \mathrm{~kg}\end{array}$ & $\begin{array}{c}486 \mathrm{~W} \\
\text { (Solar panels) }\end{array}$ & $\begin{array}{c}2000 \mathrm{~m} / \mathrm{s} \\
\text { (Chemical propulsion system) }\end{array}$ \\
\hline OKEANOS & $\begin{array}{l}\text { Wet: } 1400 \mathrm{~kg} \\
\text { Dry: } 1250 \mathrm{~kg}\end{array}$ & $\begin{array}{c}5 \mathrm{~kW} \\
\text { (Thin-film solar cells) }\end{array}$ & $\begin{array}{c}7000 \mathrm{~m} / \mathrm{s} \\
\text { (High-Isp ion engines) }\end{array}$ \\
\hline
\end{tabular}

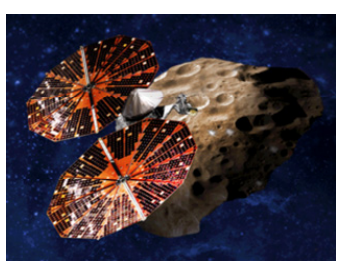

(a) Lucy

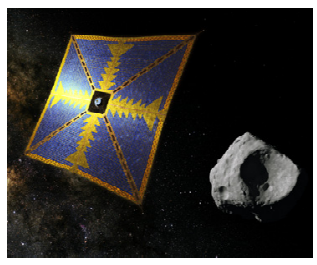

(b) OKEANOS
Fig. 1. Exploration missions of Jupiter Trojan asteroids.

Table 2. Small celestial body and outer solar system exploration.

\begin{tabular}{|c|c|c|c|c|c|c|c|}
\hline & $\begin{array}{l}\text { Asteroid inside } \\
\text { the main belt } \\
\end{array}$ & Comet & $\begin{array}{l}\text { Jupiter } \\
\text { zone }\end{array}$ & \begin{tabular}{|l} 
Saturn \\
zone
\end{tabular} & Uranus & Neptune & $\begin{array}{l}\text { Pluto, } \\
\text { EKBO }\end{array}$ \\
\hline Flyby & $\bullet \mathrm{U}, \mathrm{E}, \mathrm{C}$ & $\bullet \mathrm{J}, \mathrm{U}, \mathrm{E}, \mathrm{R}$ & $\begin{array}{l}\text { UU } \\
\text { U:Lucy } \\
\text { J:OKEANOS }\end{array}$ & $\bullet$ & $\bullet u$ & ๑u & $\begin{array}{l}\text { UU:New } \\
\text { Horizons }\end{array}$ \\
\hline $\begin{array}{l}\text { Orbit/ } \\
\text { Rendez } \\
\text { vous }\end{array}$ & $\begin{array}{l}\bullet J, U, R \\
\mathbf{U} U\end{array}$ & $\bullet E$ & \begin{tabular}{|l|l} 
UU \\
UU:Juno \\
EIJ:Juice \\
U:EJSM \\
\end{tabular} & $\bullet u$ & au & & \\
\hline Landing & \begin{tabular}{|l|}
$\bullet J, U$ \\
$-\mathrm{E} / \mathrm{G}$ \\
\end{tabular} & $\bullet$ E/G:Philae & $\begin{array}{l}\mathrm{U} \\
\mathrm{J}: \text { OKEANOS }\end{array}$ & $\bullet$ E:Huygens & mu & & \\
\hline $\begin{array}{l}\text { Sample } \\
\text { return }\end{array}$ & $\begin{array}{l}\text { QJ:Hayabusa } \\
\text { AJ:Hayabusa2, } \\
\text { U:OSIRIS-Rex } \\
\text { E,R }\end{array}$ & $\because u$ & J:OKEANOS & & & \multirow{2}{*}{\multicolumn{2}{|c|}{$\begin{array}{l}\text { Achievements } \\
\text { - Under operation } \\
\text { Under develoment } \\
\text { Under investigation } \\
\end{array}$}} \\
\hline $\begin{array}{l}\text { Manned } \\
\text { round trip }\end{array}$ & U:ARM & & & & & & \\
\hline
\end{tabular}

\section{Direct Exploration Mission of Jupiter Trojan Asteroid by OKEANOS}

\subsection{Mission outline}

A spin-type large sail with an area of $2000 \mathrm{~m}^{2}$ (ten times larger than that of IKAROS) can be an ultra-light power generation system $(1 \mathrm{~kW} / \mathrm{kg})$ and generate high volumes of electric power in the outer planetary region $(5 \mathrm{~kW}$ at $5.2 \mathrm{AU})$ by attaching thin-film solar cells over the entire surface of the sail membrane, as shown in Fig. 2(a).

A high-performance ion engine with a specific impulse of 7000 seconds (two times larger than that of Hayabusa or Hayabusa-2) is driven by this high volume of electric power, and is capable of achieving a large $\Delta \mathrm{V}$ in the outer planetary region, as shown in Fig. 2(b).

The mission sequence is shown in Fig. 3. OKEANOS is supposed to rendezvous with a Jupiter Trojan asteroid around the L4 point of the Jupitar-Sun system assisted by the gravities of Earth and Jupiter. After arriving at the Trojan asteroid, a lander separates from OKEANOS to collect surface and underground samples and perform in-situ analysis in Plan-A/B. In addition, the lander delivers samples to OKEANOS for returning the samples to Earth in Plan-B. In this mission, by probing the Trojan asteroids directly, it is possible to empirically examine the planetary movement model of gas giants as the latest hypothesis of solar system formation. The orbits of the Itokawa, Ryugu and Trojan asteroids are shown in Fig. 4.

During the cruising phase, OKEANOS performs several innovative first-class astronomical science observations. The long distance and period from the launch to the swing-by at Jupiter will give us a good opportunity to explore the solar
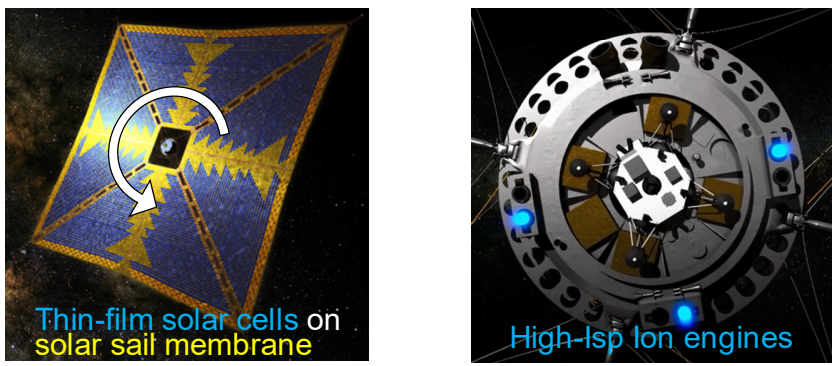

(a) Ultra-light and high volume power generation system (b) High-Isp ion engines

Fig. 2. Solar power sail system.

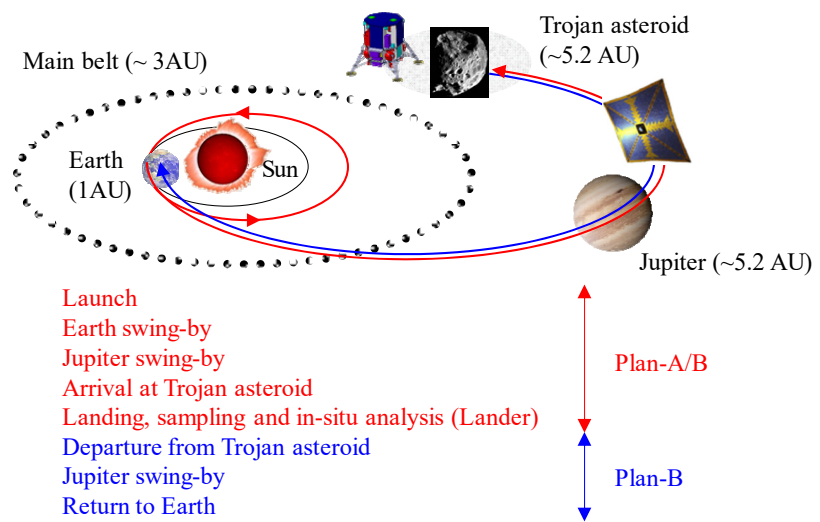

Fig. 3. Mission sequence.

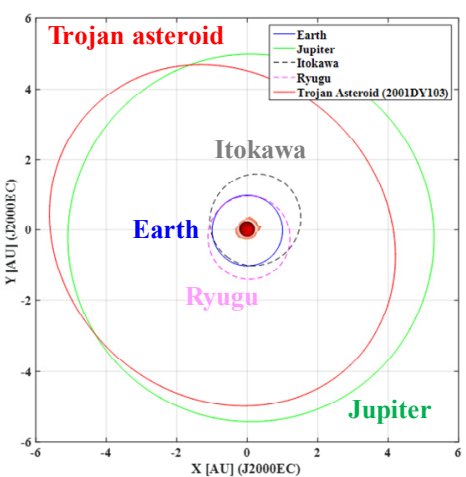

Fig. 4. Orbits of Itokawa, Ryugu and Trojan asteroids.

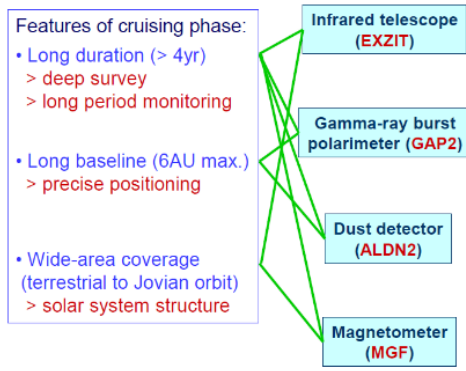

Fig. 5. Cruising phase science. 
system between the Earth and Jupiter, and to execute long-period and long-baseline observation for astronomy as shown in Fig. 5. The EXZIT infrared telescope, GAP2 gamma-ray burst polarimeter, ALDN2 dust detector and MGF magnetometer utilizes features of the cruising phase. They are contributing greatly to the progression of planetary science, astronomy and space physics.

\subsection{Success criteria}

This is an engineering mission, like Hayabusa was for Hayabusa-2. The success criteria of this mission are shown in Table 3. Performing scientific observation is considered full success and pioneering the new scientific field is an extra success. Even in Plan-B, returning a sample is an extra success.

Table 3. Success criteria.

\begin{tabular}{|c|c|c|c|}
\hline & Minimum & Full & Extra \\
\hline $\begin{array}{l}\text { Navigation } \\
\text { Technology }\end{array}$ & $\begin{array}{l}\text { - Deploy the power } \\
\text { sail and generate } \\
\text { the required electric } \\
\text { power } \\
\text { - Drive the high-lsp } \\
\text { ion engines and } \\
\text { perform required } \Delta V\end{array}$ & $\begin{array}{l}\text { - Rendezvous with } \\
\text { the Trojan asteroid } \\
\text { - Perform relative } \\
\text { position controlling } \\
\text { using image } \\
\text { navigation }\end{array}$ & $\begin{array}{l}\text { - Perform sample } \\
\text { return } \\
\text { (in Plan-B) }\end{array}$ \\
\hline $\begin{array}{l}\text { Exploration } \\
\text { Technology }\end{array}$ & $\begin{array}{l}\text { - Required bus } \\
\text { systems properly } \\
\text { work }\end{array}$ & $\begin{array}{l}\text { - Lander performs a } \\
\text { soft landing } \\
\text { - Perform sampling } \\
\text { and in-situ } \\
\text { analyses }\end{array}$ & $\begin{array}{l}\text { - Perform re-entry } \\
\text { capsule landing } \\
\text { (in Plan-B) }\end{array}$ \\
\hline $\begin{array}{l}\text { Scientific } \\
\text { Observation }\end{array}$ & & $\begin{array}{l}\text { - Perform scientific } \\
\text { observation }\end{array}$ & $\begin{array}{l}\text { - Pioneer the new } \\
\text { scientific field } \\
\text { through scientific } \\
\text { observation }\end{array}$ \\
\hline
\end{tabular}

\section{OKEANOS System Design}

\subsection{Trajectory design}

If the diameter of the asteroid is more than $20 \mathrm{~km}$, there is a high probability of it being a D/P type. From the point of view of landing, the gravity should be as small as possible. Therefore, Trojan asteroids with diameters of $20 \sim 30 \mathrm{~km}$ are selected as target candidates. The prerequisite of the trajectory design is as follows;

-Launch: mid 2020s

-C $3: 30 \mathrm{~km}^{2} / \mathrm{s}^{2}$

-IES thrust and specific impulse:

$25.6 \mathrm{mN}$ per unit, Isp $=6849 \mathrm{sec}$ at BOL

$22.2 \mathrm{mN}$ per unit, Isp $=5936 \mathrm{sec}$ at $\operatorname{MOL}(20000 \mathrm{~h})$

-IES number of operating units: 3 units (max)

-IES throttling model: Fig. 6

-IES operation rate: $80 \%(\max )$

-Sun angle: $45 \mathrm{deg}$ (max)

If the initial mass at the time of Earth departure/launch is $1400 \mathrm{~kg}$, a 2-year EDVEGA can be established tightly. Thus, the upper limit of OKEANOS mass is defined as $1400 \mathrm{~kg}$. With respect to IES power, the duration from Jupiter to 2009SK78 is shown in Table 4. The smaller the IES power, the longer the duration. If the upper limit of IES power is 2600 $\mathrm{W}$ at 5.2 AU, the fastest scenario and trajectory to 2009SK78 in Plan-A are shown in Table 5 and Fig. 7, respectively. The total duration is less than 12 years. The scenario to 2009SK78 in Plan-B is shown in Table 6 . The $\Delta \mathrm{V}$ is $6000 \sim 7000 \mathrm{~m} / \mathrm{s}$. There are two or three targets around the L4 point for every launch year.

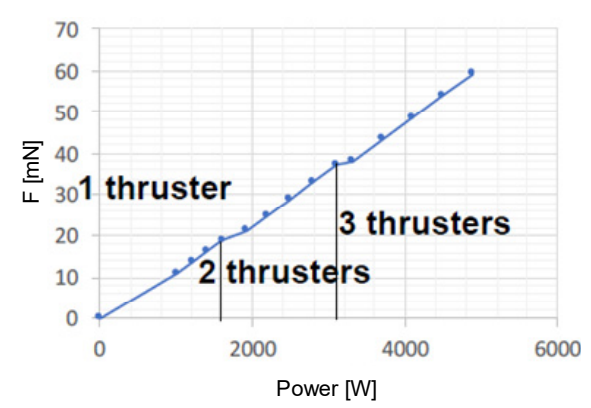

Fig. 6. IES throttling model.

Table 4. The duration from Jupiter to 2009SK78.

\begin{tabular}{|c|c|c|}
\hline IES power [W] & Duration [year] & IES $\Delta \mathrm{V}[\mathrm{m} / \mathrm{s}]$ \\
\hline 2600 & 7.33 & 3986 \\
\hline 2400 & 7.57 & 3776 \\
\hline 2200 & 7.86 & 3557 \\
\hline 2000 & 8.14 & 3394 \\
\hline 1800 & 8.68 & 3144 \\
\hline 1600 & 9.41 & 2932 \\
\hline
\end{tabular}

Table 5. The fastest scenario to 2009SK78 in Plan-A.

\begin{tabular}{|l|c|c|c|}
\hline Phase & Start & End & IES $\Delta V[\mathrm{~m} / \mathrm{s}]$ \\
\hline 2-year EDVEGA & $19 / 11 / 2024$ & $21 / 9 / 2026$ & 1777 \\
\hline Earth to Jupiter & $21 / 9 / 2026$ & $16 / 5 / 2029$ & - \\
\hline Jupiter to Asteroid & $16 / 5 / 2029$ & $11 / 9 / 2036$ & 3986 \\
\hline
\end{tabular}

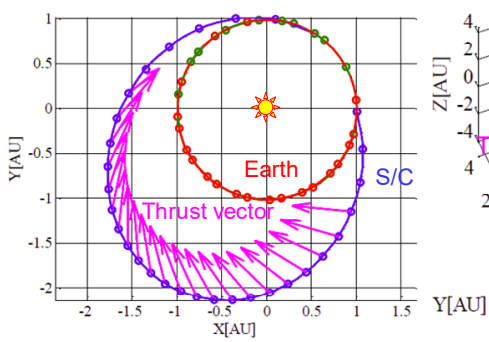

(a) 2-year EDVEGA

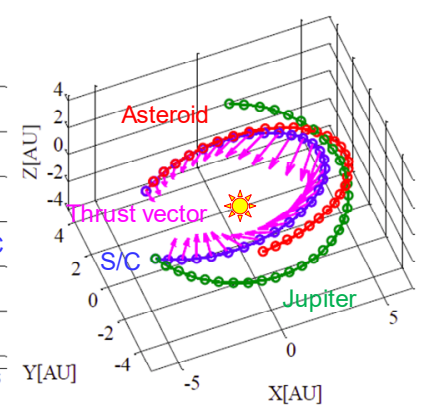

(b) Jupiter to asteroid
Fig. 7. The fastest trajectory to 2009SK78 in Plan-A.

Table 6. The scenario to 2009SK78 in Plan-B.

\begin{tabular}{|l|c|c|c|}
\hline Phase & Start & End & IES $\Delta V[\mathrm{~m} / \mathrm{s}]$ \\
\hline 2-year EDVEGA & $19 / 11 / 2024$ & $21 / 9 / 2026$ & 1777 \\
\hline Earth to Jupiter & $21 / 9 / 2026$ & $16 / 5 / 2029$ & - \\
\hline Jupiter to Asteroid & $16 / 5 / 2029$ & $1 / 1 / 2038$ & 2049 \\
\hline Proximity Op. & $1 / 1 / 2038$ & $1 / 1 / 2039$ & - \\
\hline Asteroid to Jupiter & $1 / 1 / 2039$ & $3 / 2 / 2053$ & 2441 \\
\hline Jupiter to Earth & $3 / 2 / 2053$ & $30 / 9 / 2055$ & - \\
\hline
\end{tabular}

\subsection{Initial design}

The initial design of OKEANOS has been conducted. Wet mass, which includes a $100 \mathrm{~kg}$ lander, is $1351 \mathrm{~kg}$. This means that the trajectory plan is feasible, as the estimated OKEANOS mass satisfies the upper limit $1400 \mathrm{~kg}$.

The structural design and equipment layout of OKEANOS in Plan-A are shown in Figs. 8 and 9. The entire structure is composed of octagonal side panels and upper/lower panels. A cylinder structure and sail storage structure are equipped in- 
side and outside of the octagon, respectively. The overview of each sub-system is as follows.

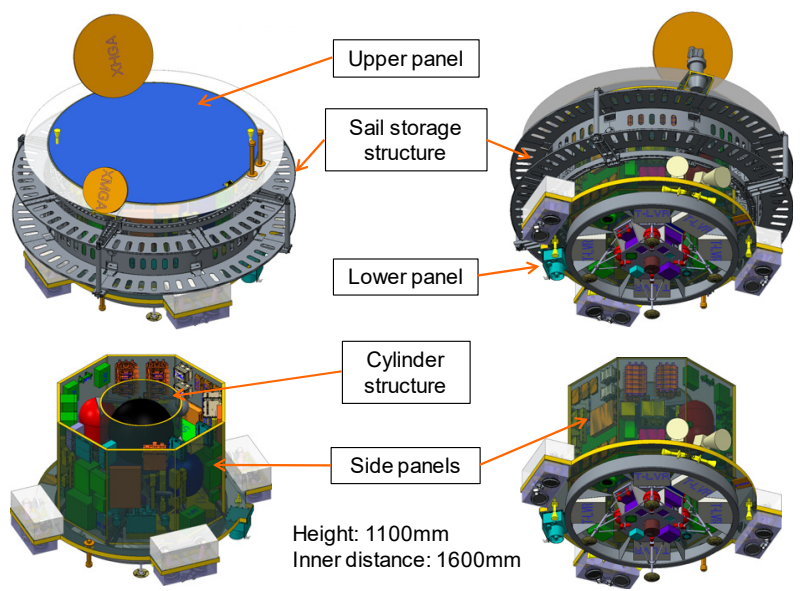

Fig. 8. OKEANOS structural design.
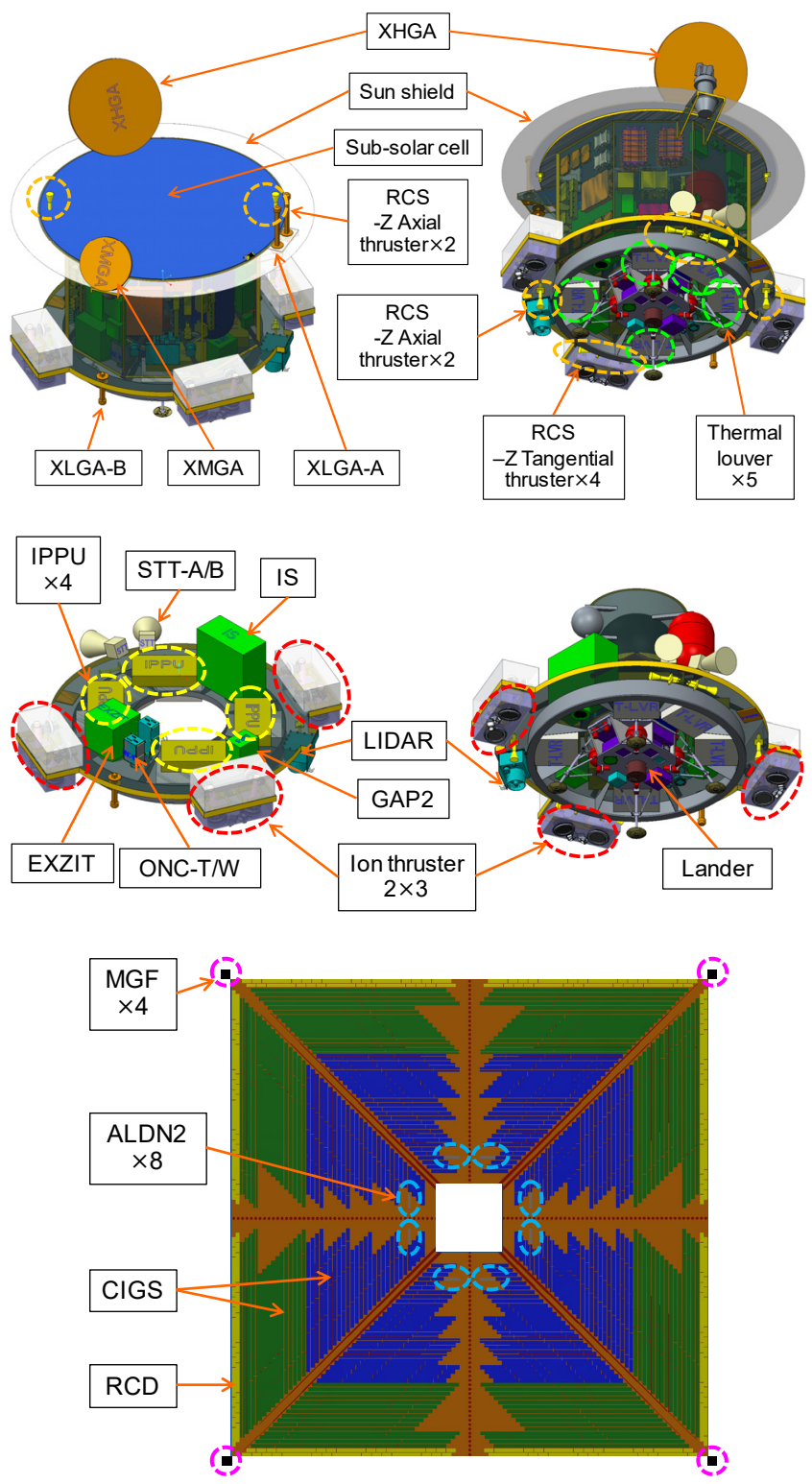

Fig. 9. OKEANOS equipment layout.
Since the voltage generated by solar cells is significantly changed by the temperature, a sub-solar cell mounted on the upper panel and thin-film solar cell (CIGS) on the sail are switched between each other based on the distance from the Sun.

The IES, RCD and RCS are used to control attitude. The attitude control using RCD is shown in Fig. 10. For reorientation, the magnitude of solar radiation pressure force can be changed using RCD. For spin control, the horizontal component of solar radiation pressure force can be obtained using advanced RCD. ${ }^{6}$ The attitude control using IES is shown in Fig. 11. Throttling control provided by IES in accordance with the spin motion makes an imbalance of force that generates torque for reorientation. Utilizing the cant angle of the IES with respect to the spin axis generates torque for spin control.

The structural design and equipment layout of the lander is shown in Fig. 12. It is composed of an octagonal shape with legs at the bottom. Unlike the Philae, the lander is equipped with an RCS consisting of 12 cold gas thrusters. Since the Sun distance of Trojan asteroids is about 5.2 AU, significant power generation by solar cells cannot be expected. Therefore, the lander is exclusively driven by a battery. Science equipment is assigned a mass of $20 \mathrm{~kg}$, including sampling devices. The wet mass is satisfying the mass of $100 \mathrm{~kg}$ assigned to the lander.

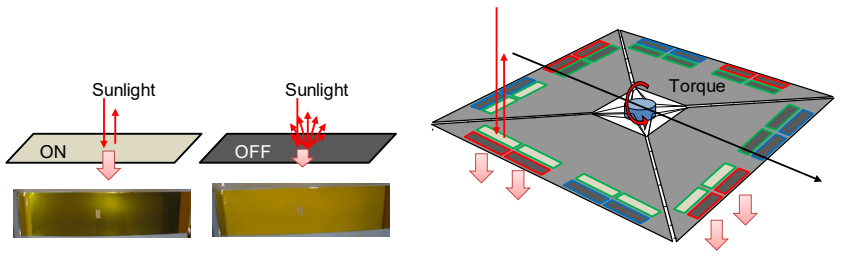

(a) Reorientation

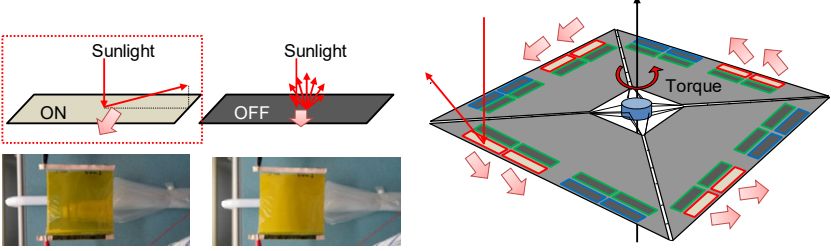

(b) Spin control

Fig. 10. Attitude control using RCD.

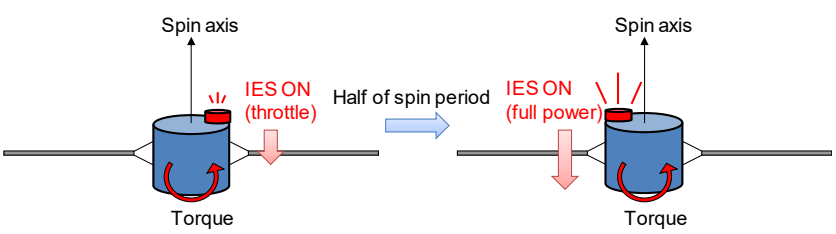

(a) Reorientation

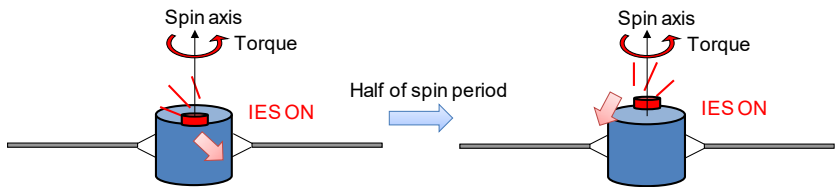

(b) Spin control

Fig. 11. Attitude control using IES. 


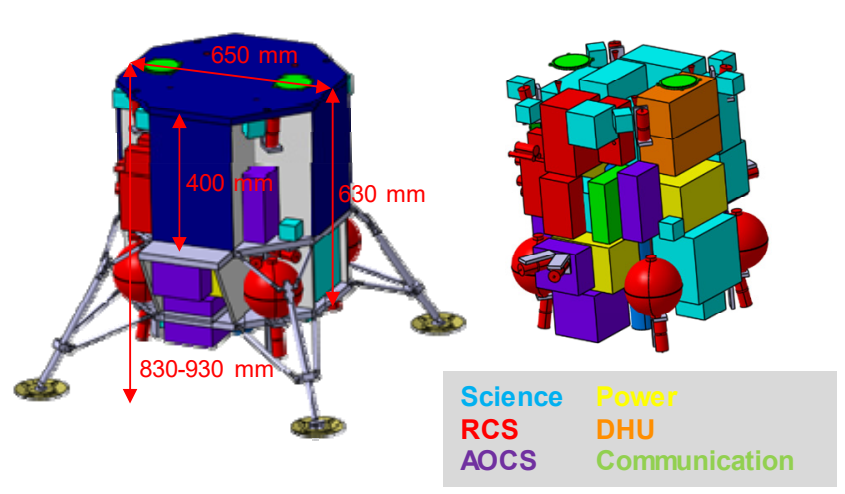

Fig. 12. Structural design and equipment layout of the lander.

\section{Mission Analysis at Trojan Asteroid}

\subsection{Decent, landing and ascent sequence}

Since OKEANOS has a large sail and spins, it is very risky for it to land on the asteroid itself. A lander will therefore separate and perform the landing, sampling, and in-situ analysis. It delivers a sample to OKEANOS by rendezvous and docking to return the sample in Plan-B.

The operational policy after arrival at the Trojan asteroid is as shown in Fig. 13. OKEANOS stays at the home position (HP), whose altitude is $250 \mathrm{~km}$ from the asteroid, in the case of operation. When the lander-separation operation starts, OKEANOS descends to an altitude of $1 \mathrm{~km}$ to separate the lander. After separation, the lander starts its to conduct sampling and in-situ analysis.

In Plan-A, OKEANOS returns to HP. In Plan-B, OKEANOS ascends to an altitude of $50 \mathrm{~km}$ (docking altitude) and keeps that position until rendezvous docking is completed. After finishing the in-situ analysis of the samples, the lander starts ascending toward OKEANOS, and performs rendezvous docking. Then, the samples inside the lander are transferred to the re-entry capsule of OKEANOS. Finally, the lander is again separated from OKEANOS to reduce the system weight during the return trip to Earth.

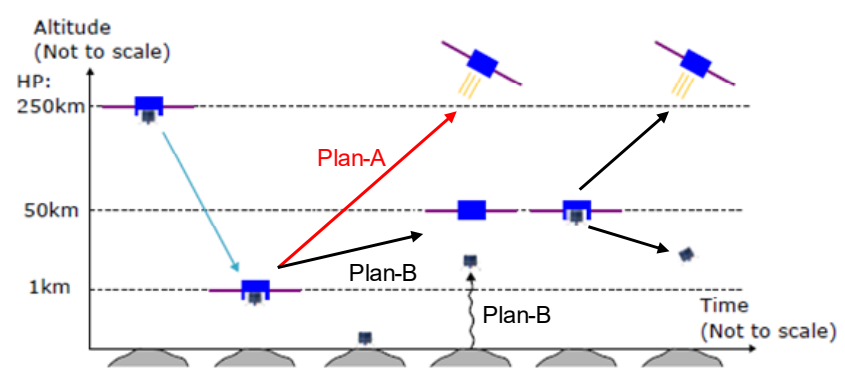

Fig. 13. Operational policy at the Trojan asteroid.

\subsection{Sampling and in-situ analysis}

The lander has two sampling devices to collect the surface and underground samples, as shown in Fig. 14. ${ }^{7}$ For the former, a sampler horn is used. In the Hayabusa mission, gun powder was used as the projector driver. On the other hand, in this mission, high-pressure gas is used as a projector driver to prevent contamination. For the latter, a pneumatic drill excavates a 1-m regolith layer using high-pressure gas. This device has a telescopic structure, as shown in Fig. 15. At first, exten- sion and excavation are performed at the same time. Next, additional high-pressure gas is released and underground samples are collected. If there is a rock, a projectile is shot to generate fragments of the samples.

A sample container as shown in Fig. 14 and Fig. 16 shows an interface device between the sampling devices and the high-resolution mass spectrometer (HRMS). On top of the sampler, a branch pipe is attached in order to distribute the samples collected to several sample boxes. The sample boxes are attached compartments in the sample container. The sampling operation is designed to collect at least $1 \mathrm{mg}$ of sample in each sample box. After the sampling operation, the sample boxes are heated by heaters, and the evaporated samples are moved to the mass spectrometer where they are analyzed. The isotopic ratios of CHON elements, and organic molecules are investigated using HRMS.

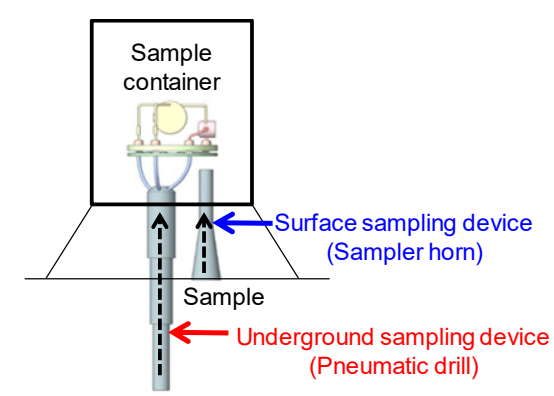

Fig. 14. Sampling devices and sample container.
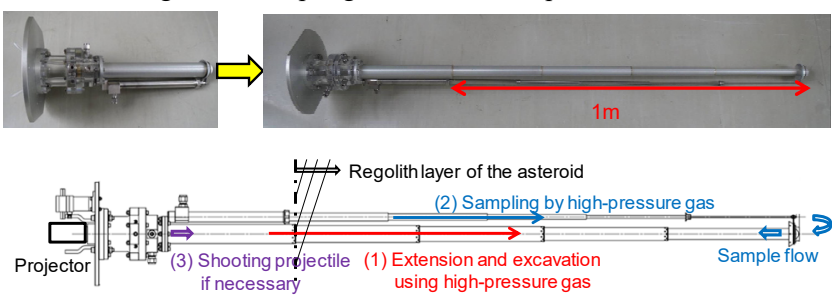

Fig. 15. Underground sampling device.

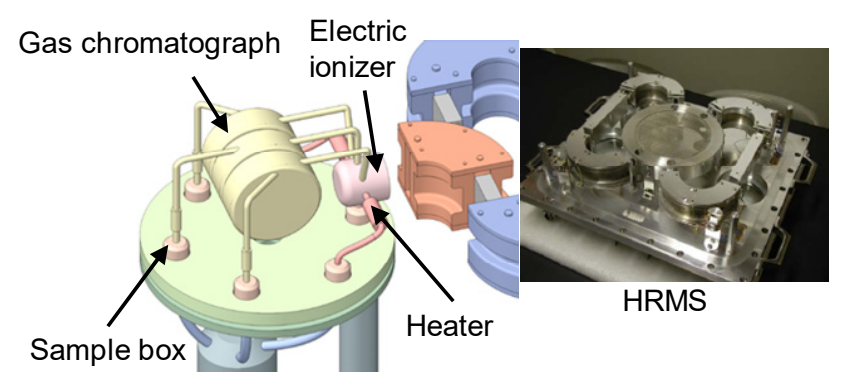

Fig. 16. Sample container.

\subsection{Rendezvous docking and sample transfer}

Figure 17 describes the sequence of the rendezvous phase in Plan-B. The lander and OKEANOS are equipped with a newly developed radio-frequency ( $R F)$ sensor. It utilizes the characteristics of an active integrated phased array antenna (AIPAA), which is shown in Fig. 18, to determine the relative relationship between the two antennas. ${ }^{8)}$ This sensor makes it possible to estimate the position and attitude without using a conventional system such as GPS.

First, the lander takes off and ascends vertically from the surface of the asteroid until it reaches an altitude of $8 \mathrm{~km}$, at 
which time the ONC can capture the whole image of the asteroid (Seq. 1). Next, the lander uses the RF sensor and the ONC to move beneath OKEANOS until it reaches a relative distance of about $1 \mathrm{~km}$ (Seq. 2). In the relative distance of 1 $\mathrm{km}$ to about $100 \mathrm{~m}$, the lander uses only the IRU and ascends vertically toward OKEANOS applying impulsive $\Delta \mathrm{V}$ (Seq. 3). When the relative distance reaches about $100 \mathrm{~m}$, the lander captures the LED markers illuminated on the bottom side of OKEANOS using the ONC. Then, it performs optical navigation until it reaches a relative distance of about $2 \mathrm{~m}$ (Seq. 4). The IRU is used in all sequences to observe the angular velocity of the lander.

Because OKEANOS is spinning and the delay time is large, the docking is to be conducted autonomously in Plan-B, as shown in Fig. 19. At first, the lander extends the extension boom. Next, the lander approaches OKEANOS to insert the boom into the holding space. Due to the tapered shape of the holding space, the tip of the boom is guided to the connection part regardless of slight error in guidance, navigation and control. The tip of the boom is connected using electromagnetic force. This makes the second separation of the lander easier.

Figure 20 shows the sample transfer sequence in Plan-B. The samples are first transferred to a container, called "sample catcher," via the induction pathway at the sampling. The extension mast pushes the sample catcher up to the re-entry capsule after docking is completed.

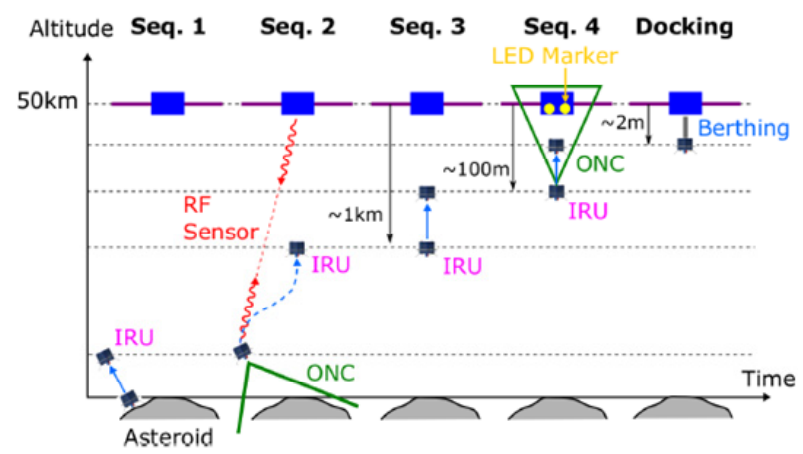

Fig. 17. Sequence of the rendezvous phase in Plan-B.

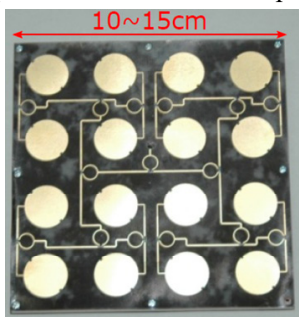

Fig. 18. Appearance of the AIPAA.

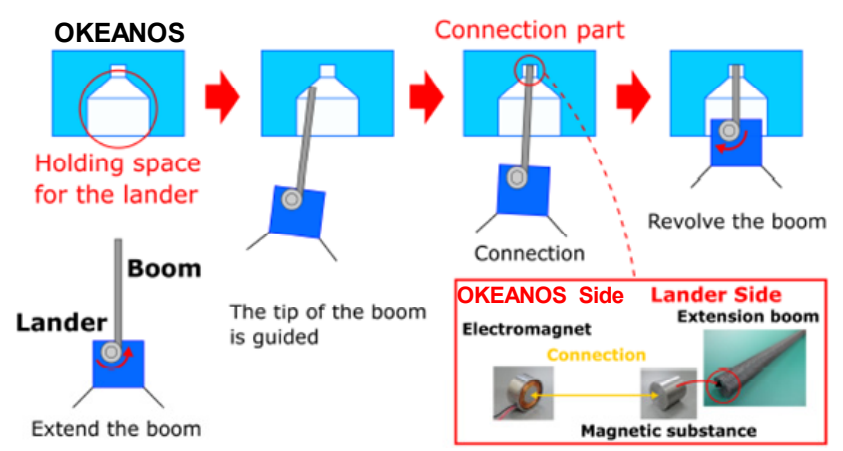

Fig. 19. Sequence of the berthing method in Plan-B.
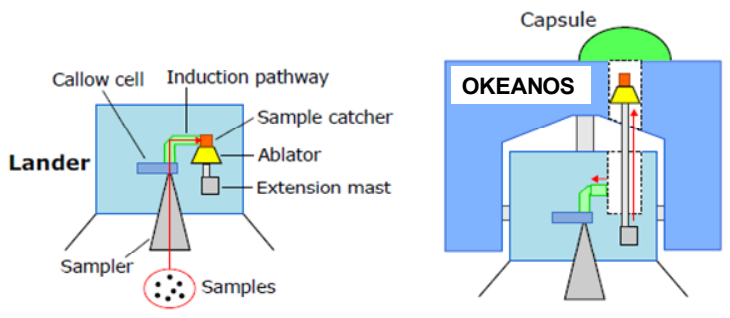

Fig. 20. Schematic chart of the sample transfer in Plan-B.

\section{Conclusion}

In this paper, the system design for OKEANOS was shown and the mission analysis process at a Trojan asteroid was presented. (1) The upper limit of OKEANOS mass was defined as $1400 \mathrm{~kg}$ to enable a 2-year EDVEGA. The smaller the IES power is, the longer the duration becomes. The minimum duration to arrive at a Trojan asteroid is less than 12 years. The $\Delta \mathrm{V}$ for the sample return from a Jupiter Trojan asteroid is $6000 \sim 7000 \mathrm{~m} / \mathrm{s}$. (2) To collect the underground samples, a pneumatic drill excavates samples from the regolith layer at a depth of $1 \mathrm{~m}$ using high-pressure gas. Samples of at least $1 \mathrm{mg}$ in weight should be collected. They are heated and then analyzed using a mass spectrometer. (3) In the rendezvous phase, an RF sensor is used to estimate the position and attitude. In the docking phase, the extension boom is inserted into the holding space. After docking is completed, the other extension mast pushes the sample catcher up to the re-entry capsule.

\section{References}

1) Mori, O., Tsuda, Y., Sawada, H., Funase, R., Saiki, T., Yamamoto, T., Yonekura, K., Hoshino, H., Minamino, H., Endo, T., Shirasawa, Y., Mimasu, Y., Ono, G. and Kawaguchi, J.: Development and Operation Summary of World's First Solar Power Sail IKAROS, Journal of Space Technology and Science, 27 (2013), pp. 20-37.

2) Kawaguchi, J.: A Solar Power Sail Mission for a Jovian Orbiter and Trojan Asteroid Flybys, COSPAR04-A-01655, 2004.

3) Morbidelli, A., Levison, H. F., Tsiganis, K. and Gomes R.: Chaotic Capture of Jupiter's Trojan Asteroids in the Early Solar System, Nature 435 (2005), pp.462-465.

4) Mori, O., Saiki, T., Kato, H., Tsuda, Y., Mimasu, Y., Shirasawa, Y., Boden, R., Matsumoto, J., Chujo, T., Kikuchi, S., Kikuchi, J., Oki, Y., Akatsuka, K., Iwata, T., Okada, T., Yano, H., Matsuura, S., Nakamura, R., Kebukawa, Y., Aoki, J. and Kawaguchi, J.: Jovian Trojan Asteroid Exploration by Solar Power Sail-craft, Trans. JSASS Aerospace Tech. Japan, 14, ists30 (2016), pp.Pk_1-Pk_7.

5) Levison, H. F., Olkin, C., Noll, K. S., Marchi, S. and the Lucy Team: LUCY: Surveying the Diversity of the Trojan Asteroids: The Fossils of Planet Formation, Lunar Planet. Sci. Conf. 48, \#2025, The Woodlands, 2017.

6) Ishida, H., Chujo, T., Mori, O. and Kawaguchi, J.: Optimal Design of Advanced Reflectivity Control Device for Solar Sails Considering Polarization Properties of Liquid Crystal, 26th International Symposium on Space Flight Dynamics, ISSFD-2017-061, Matsuyama, 2017.

7) Matsumoto, J., Okamoto, C., Oki, Y., Nakamura, T. and Aoki, J. Sampling Operation for the Jupiter Trojan Asteroid Exploration, 31st International Symposium on Space Technology and Science, 2017-k-17, Matsuyama, 2017.

8) Wu, C. T. M., Choi, J., Kawasaki, S. and Itoh, T.: A Novel Miniaturized Polarization Orthogonalizing Active Retrodirective Antenna Array for Satellite Use, IMS2013, TH3C-3, Seattle, 2013. 